\title{
Tiotropium as essential maintenance therapy in COPD
}

\section{Decramer}

ABSTRACT: Over the past decade, several large-scale clinical trials have been performed to assess the impact of pharmacological treatments on patient-centred outcomes such as dyspnoea, exercise tolerance, exacerbations and health-related quality of life (HRQoL) in patients with chronic obstructive pulmonary disease (COPD).

Tiotropium, a once-daily inhaled anticholinergic agent that works through prolonged muscarinic $\mathrm{M}_{3}$ receptor blockade, has consistently been shown to provide sustained improvements in lung function parameters. Furthermore, several prospective trials have shown that tiotropium improves exercise tolerance and augments the beneficial effects of pulmonary rehabilitation. Beyond these important physiological outcomes, tiotropium has been shown to reduce dyspnoea, decrease the frequency of exacerbations and improve HRQoL in studies of $\leqslant 1 \mathrm{yr}$ in duration. Such improvements in patient-centred outcomes may allow patients to increase their activity levels, thereby interrupting the downward spiral of chronic inactivity that leads to physical deconditioning and further reductions in exercise tolerance.

Recently, combination therapies of two long-acting bronchodilators have been examined more closely regarding their potential to provide patients with superior symptom relief compared with that provided by single-agent therapy.

Because maintenance treatment with tiotropium provides consistent and sustained improvements in many relevant clinical outcomes of chronic obstructive pulmonary disease, it may reduce the progression of the disease. This hypothesis is being tested in the ongoing Understanding the Potential Long-term Impacts on Function with Tiotropium (UPLIFT) trial.

KEYWORDS: Bronchodilators, chronic obstructive pulmonary disease, dyspnoea, exercise tolerance, quality of life, tiotropium

$\mathbf{T}$ he physiological hallmark of chronic obstructive pulmonary disease (COPD) is expiratory flow limitation. However, it is probably the resultant air trapping and associated hyperinflation that provide the mechanistic link between the physiological impairment and the characteristic symptoms of COPD, such as dyspnoea, exercise intolerance, exacerbations and reduced health-related quality of life (HRQoL; fig. 1).

Expiratory flow limitation causes air trapping and hyperinflation when there is insufficient expiratory time to allow adequate lung emptying. This causes the patient to feel dyspnoeic very quickly when the minute ventilation or respiration rate is increased, e.g. during exercise or an exacerbation. Although dyspnoea is the primary driver to seek medical attention, patients with COPD may mask this symptom for some time through lifestyle modifications, e.g. by avoiding situations that demand physical activity [1].
Chronic inactivity leads to muscle deconditioning, which further impairs exercise performance [2]. Avoiding exercise leads to worsening of the disease and, ultimately, to further deterioration of the patient's HRQoL [3].

The Global Initiative for Chronic Obstructive Lung Disease (GOLD) guidelines recommend tiotropium or long-acting $\beta_{2}$-agonists (LABAs) as first-line maintenance treatment in COPD [4]. Although the choice of agent may be influenced by individual patient characteristics, the ability of the therapy to improve not only lung function but also patient-centred outcomes, such as dyspnoea, exercise tolerance, exacerbations and HRQoL, is an important consideration.

Effective bronchodilation reduces airflow limitation, with consequent reductions in air trapping and hyperinflation, which relieves dyspnoea and improves exercise tolerance, thereby interrupting the cycle of chronic inactivity and physical deconditioning. This ultimately leads to improvements
CORRESPONDENCE

M. Decramer

Respiratory Division

Katholieke Universiteit Leuven

University Hospital

Herestraat 49

3000 Leuven

Belgium

Fax: 3216346803

E-mail: Marc.Decramer@

uz.kuleuven.ac.be

CONFLICT OF INTEREST STATEMENT $M$. Decramer has received honoraria from Boehringer Ingelheim (Ingelheim, Germany) and Pfizer (New York, NY, USA) for his participation at symposia. He has also acted as a consultant to Boehringer Ingelheim, Pfizer, AstraZeneca (London, UK), GlaxoSmithKline (London, UK), Altana (Konstanz, Germany) and Zambon (Bresso, Italy). M. Decramer has no financial conflict or other relationship with a commercial entity in relation to this article. 


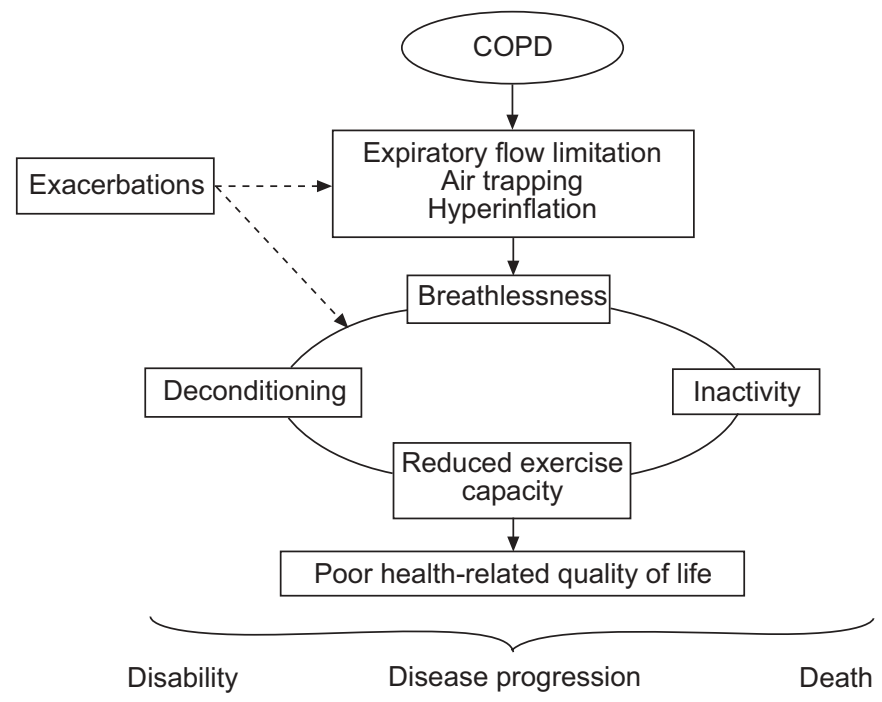

FIGURE 1. The clinical course of chronic obstructive pulmonary disease (COPD).

in patients' HRQoL. The aim of this article is to review the effects of LABAs and tiotropium on patient-centred outcomes. The National Institute of Clinical Excellence (NICE) recently published clinical guidelines on the management of COPD, which included summary tables of the results from systemic reviews or randomised controlled trials of long-acting bronchodilators on key clinical outcomes [5].

\section{EFFECT OF LONG-ACTING BRONCHODILATORS ON PATIENT-CENTRED OUTCOMES Long-acting anticholinergic agents}

Tiotropium, a once-daily inhaled anticholinergic agent that works through prolonged muscarinic $\mathrm{M}_{3}$ receptor blockade, has consistently been shown to have significant beneficial effects on dyspnoea, exercise tolerance, HRQoL and exacerbations in patients with COPD. Six publications were included in the NICE guidelines, which examined the effect of tiotropium versus placebo, ipratropium or salmeterol on patient-centred outcomes (table 1) [5]. Since the publication of the guidelines, seven further randomised, controlled, large-scale (i.e. $\geqslant 100$ patients) trials of $\geqslant 4$ weeks' duration, focusing on patientcentred outcomes, have been performed (table 2) [12-18].

Compared with placebo, tiotropium improved the transition dyspnoea index (TDI) focal score, a measure of dyspnoea during day-to-day activities, in seven out of the eight studies in which this end-point was assessed $(p<0.05)[8-10,12,13,16]$. The proportion of patients who achieved a score of $\geqslant 1$ (corresponding to a clinically important difference) in TDI focal score was also significantly greater in the tiotropium group versus the placebo group $(\mathrm{p}<0.05)$ at study end in four of the studies [8-10, 13]. Further, tiotropium decreased the Borg score, a measure of exertional dyspnoea, at a standardised time near end-exercise (isotime) after 6 weeks of treatment in both studies that assessed this end-point $(\mathrm{p}<0.01)[12,16]$. The use of short-acting bronchodilators for symptomatic relief also provided an indication of the degree of dyspnoea experienced by the patient. Rescue medication use was consistently reduced in the tiotropium group compared with the placebo group $(p<0.05)[7-9,12,13,16,18]$.

As mentioned previously, such reductions in dyspnoea may allow patients to increase their exercise tolerance. Indeed, compared with placebo, tiotropium has been shown to increase the constant work-rate cycle ergometry endurance time after 6 weeks of treatment $(p<0.01)[12,16]$, and increase the mean distance walked during the shuttle walk test after 12 weeks of treatment $(p<0.05)$ [17]. The beneficial effects of pulmonary

TABLE 1 Summary of results of studies on long-acting anticholinergic agents

\begin{tabular}{|c|c|c|c|c|c|c|c|c|c|c|c|c|c|}
\hline First author [ref.] & $\begin{array}{l}\text { Sample } \\
\text { size }\end{array}$ & $\begin{array}{c}\text { Duration } \\
\text { weeks }\end{array}$ & Drug & $\begin{array}{c}\text { Dose } \\
\mu g\end{array}$ & FEV 1 & FVC & $\begin{array}{c}\text { Diary } \\
\text { symptoms }\end{array}$ & Night & Rescue & Dyspnoea & $\begin{array}{c}\text { Exercise } \\
\text { test }\end{array}$ & HRQoL & Exacerbations \\
\hline \multicolumn{14}{|l|}{ Versus placebo } \\
\hline LITTNER [6] & 169 & 4 & Tiotropium & 4.5 & $\uparrow$ & $\uparrow$ & NA & NA & NA & NA & NA & NA & NA \\
\hline LITTNER [6] & 169 & 4 & Tiotropium & 9 & $\uparrow$ & $\uparrow$ & NA & NA & NA & NA & NA & NA & NA \\
\hline LITTNER [6] & 169 & 4 & Tiotropium & 18 & $\uparrow$ & $\uparrow$ & NA & NA & NA & NA & NA & NA & NA \\
\hline CASABURI [8] & 921 & 52 & Tiotropium & 18 & $\uparrow$ & $\uparrow$ & $\uparrow$ & NA & $\uparrow$ & $\uparrow$ & NA & $\uparrow$ & $\uparrow$ \\
\hline DONOHUE [9] & 623 & 26 & Tiotropium & 18 & $\uparrow$ & $\uparrow$ & NA & NA & $\uparrow$ & $\uparrow$ & NA & $\uparrow$ & NA \\
\hline BRUSASCO [10] & 1207 & 26 & Tiotropium & 18 & $\uparrow$ & NA & NA & NA & NA & $\uparrow$ & NA & $\uparrow$ & $\uparrow$ \\
\hline \multicolumn{14}{|l|}{ Versus ipratropium } \\
\hline VINCKEN [11] & 535 & 52 & Tiotropium & 18 & $\uparrow$ & $\uparrow$ & NA & NA & $\uparrow$ & $\uparrow$ & NA & $\uparrow$ & $\uparrow$ \\
\hline \multicolumn{14}{|l|}{ Versus salmeterol } \\
\hline
\end{tabular}

FEV1: forced expiratory volume in one second; FVC: forced vital capacity; HRQoL: heath-related quality of life; NS: no significant benefit versus comparator; NA: not assessed; $\uparrow$ : significant benefit versus comparator group (e.g. reduced dyspnoea, increased exercise tolerance, etc.); $\downarrow$ : significant inferiority versus comparator group. Reproduced, with modifications, from [5] with permission from the publisher. 
TABLE 2 Summary of results from more recent studies on long-acting anticholinergic agents

\begin{tabular}{|c|c|c|c|c|c|c|c|c|c|c|c|c|c|}
\hline First author [ref.] & $\begin{array}{l}\text { Sample } \\
\text { size }\end{array}$ & $\begin{array}{c}\text { Duration } \\
\text { weeks }\end{array}$ & Drug & $\begin{array}{l}\text { Dose } \\
\mu \mathrm{g}\end{array}$ & FEV1 & FVC & $\begin{array}{c}\text { Diary } \\
\text { symptoms }\end{array}$ & Night & Rescue & Dyspnoea & $\begin{array}{c}\text { Exercise } \\
\text { test }\end{array}$ & HRQoL & Exacerbations \\
\hline \multicolumn{14}{|l|}{ Versus placebo } \\
\hline O'DONNELL [12] & 187 & 6 & Tiotropium & 18 & $\uparrow$ & $\uparrow$ & NA & NA & $\uparrow$ & $\uparrow$ & $\uparrow$ & NA & NA \\
\hline CASBURI [13] & 91 & 25 & Tiotropium & 18 & $\uparrow$ & $\uparrow$ & NA & NA & $\uparrow^{\#}$ & $\uparrow$ & $\uparrow$ & NS & NA \\
\hline TONNEL [14] & 554 & 36 & Tiotropium & 18 & $\uparrow$ & $\uparrow$ & NA & NA & NA & NA & NA & $\uparrow$ & NA \\
\hline VERKINDRE [17] & 100 & 12 & Tiotropium & 18 & $\uparrow$ & $\uparrow$ & NA & NA & NA & NS & $\uparrow$ & $\uparrow$ & NA \\
\hline DUSSER [18] & 1010 & 52 & Tiotropium & 18 & $\uparrow$ & $\uparrow$ & NA & NA & $\uparrow$ & NA & NA & NA & $\uparrow$ \\
\hline
\end{tabular}

FEV1: forced expiratory volume in one second; FVC: forced vital capacity; HRQoL: heath-related quality of life; NS: no significant benefit versus placebo; NA: not assessed; $\uparrow:$ significant benefit versus placebo (e.g. reduced dyspnoea, increased exercise tolerance etc.). ${ }^{\#}$ : difference between treatment groups was statistically significant in 17 of the 25 weeks; " : difference of 4.44 units in the St George's Respiratory Questionnaire total score $(p=0.055)$.

rehabilitation on exercise tolerance were also significantly enhanced with tiotropium [13].

Treatment with tiotropium consistently delayed the time to first exacerbation and reduced the number of exacerbations compared with placebo in two studies $(p<0.05)[8,10]$. Furthermore, a recent prospectively designed study has shown that tiotropium is effective in reducing exacerbations in patients with moderate-to-severe COPD over a 6-month treatment period $(p<0.05)$ [15]. More recent data confirmed previous findings, demonstrating that tiotropium significantly delayed the time to first exacerbation, as well as being significantly more effective at reducing the incidence of exacerbations, compared with placebo $(p<0.001$ for both) [18]. The reduction in exacerbations with tiotropium maintenance treatment may be partially explained by the sustained bronchodilation and consequent reduction in lung hyperinflation afforded by maintenance tiotropium treatment. Whereas patients may previously have perceived an acute deterioration in their condition as an exacerbation, after recalibration of their operating lung volumes with tiotropium treatment, their symptoms become better tolerated.

These improvements in patient-centred outcomes are accompanied by significant improvements in HRQoL versus placebo, as assessed by the St George's Respiratory Questionnaire (SGRQ), in five out of six studies [8-10,13, 14, 17]. However, in the only study that failed to show a significant improvement in HRQoL with tiotropium versus placebo, the difference between the groups exceeded the minimal clinically important difference of four units in the SGRQ total score and approached statistical significance $(p=0.055)$ at study end [13].

Two studies have compared the long-term efficacy and safety of tiotropium versus the short-acting anticholinergic agent, ipratropium. Because the study designs for each of the studies were identical, data were combined and published together [11]. Compared with ipratropium, tiotropium significantly reduced dyspnoea, the use of rescue medication and the number of exacerbations, and improved HRQoL [11].

Similarly, data were combined from two studies, which compared the long-term efficacy and safety of tiotropium versus a LABA, salmeterol and placebo [10]. Compared with salmeterol, tiotropium significantly reduced dyspnoea and the use of rescue medication in one study [9]. However, in the combined study, there were no significant differences between the tiotropium and salmeterol groups in terms of rescue medication use, dyspnoea, HRQoL or exacerbations [10].

\section{LABAs}

Sixteen studies that examined the effects of LABAs, salmeterol or formoterol on patient-centred outcomes in patients with COPD, were included in the NICE guidelines (table 3).

Although salmeterol consistently reduced the use of rescue medication compared with placebo, its effects on dyspnoea, exercise tolerance, exacerbations and HRQoL were inconsistent. For instance, compared with placebo, salmeterol improved the TDI focal score in two studies $(p<0.05)[10,21]$ and improved the Borg score after the 6-min walk test at study end in two further studies $(\mathrm{p}<0.01)[22,23]$. However, it did not significantly improve dyspnoea versus placebo at study end in three other studies that assessed this end-point $[9,19,28]$. Despite the improvement in dyspnoea in several studies, salmeterol failed to show an effect on exercise tolerance, measured using the 6-min walk test in two studies $[19,22]$. Furthermore, salmeterol did not reduce the number of exacerbations versus placebo in five out of seven studies [10, 20, 19, 22, 23]. Finally, compared with placebo, salmeterol failed to improve HRQoL, as assessed by the SGRQ or the Chronic Respiratory Disease Questionnaire, in six out of eight studies $[9,10,19,28,29,31]$.

Similarly, formoterol, another LABA, provided a consistent reduction in rescue medication use [25-27]. However, formoterol 6 or $12 \mu \mathrm{g}$ failed to show an effect on dyspnoea, and all doses failed to improve exercise tolerance [25]. Furthermore, formoterol did not reduce the number of exacerbations versus placebo in three out of four studies [25, 27, 30]. By contrast, treatment with formoterol had a positive effect on HRQoL in patients with COPD [26, 27].

In summary, the majority of findings from published studies on the effects of LABAs on patient-centred outcomes are not significant. However, compared with placebo, the combination 
TABLE 3 Summary of results of studies on long-acting $\beta_{2}$-agonists

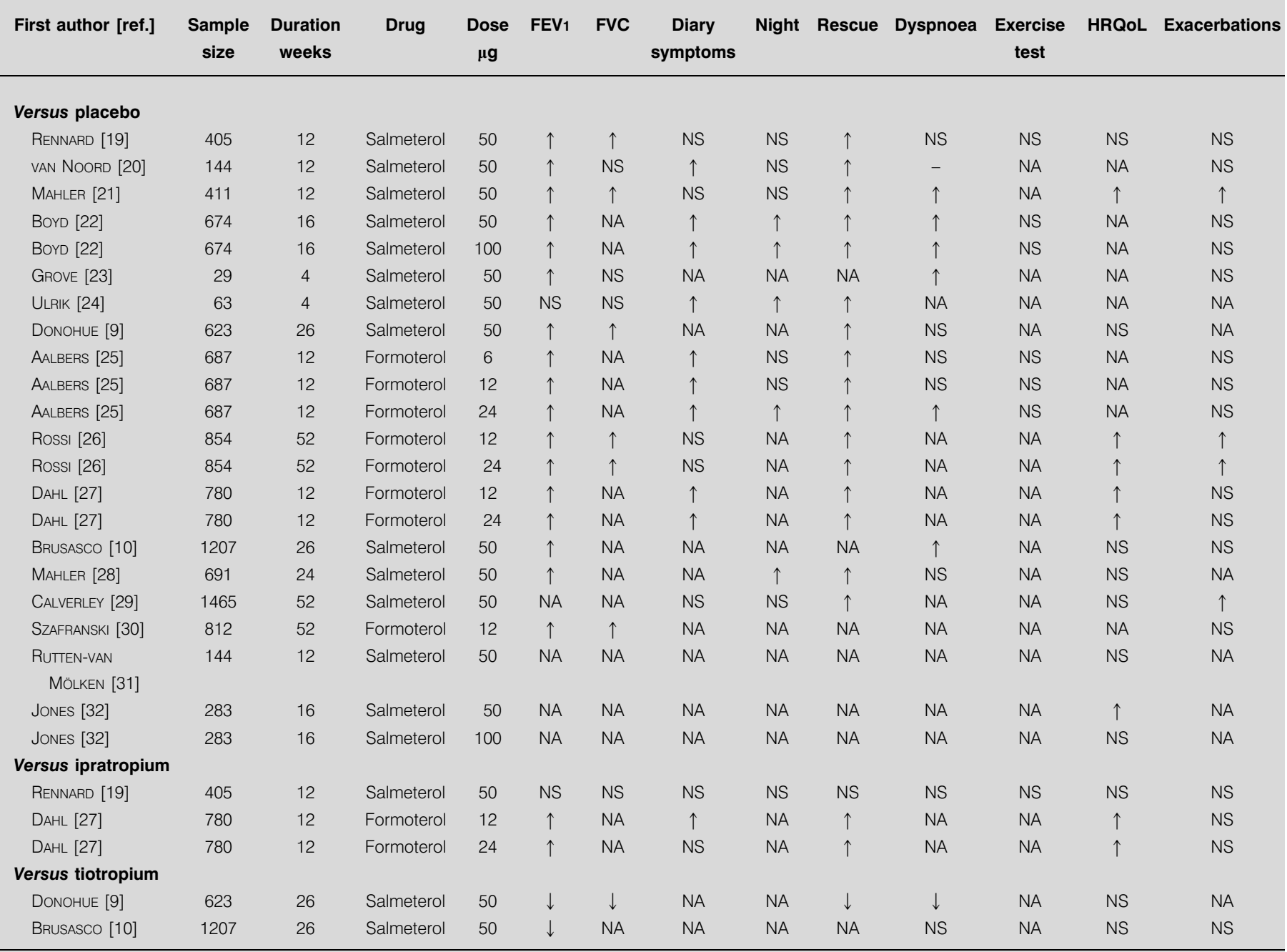

FEV1: forced expiratory volume in one second; FVC: forced vital capacity; HRQoL: health-related quality of life; NS: no significant benefit versus comparator; NA: not assessed; $\uparrow$ : significant benefit versus comparator group (e.g. reduced dyspnoea, increased exercise tolerance etc.); $\downarrow$ : significant inferiority versus comparator group Reproduced, with modifications, from [5] with permission from the publisher.

of salmeterol or formoterol with inhaled corticosteroids (ICSs) tends to have favourable effects on all patient-centred outcomes with the exception of exercise tolerance $[28,29,30,33$, 34], which has not been studied to date (table 3).

\section{LONG-ACTING BRONCHODILATOR COMBINATION STUDIES}

As the disease progresses, single-bronchodilator therapy may not adequately control COPD symptoms. In this situation, guidelines recommend optimisation of bronchodilator therapy using a combination of two long-acting bronchodilators with different pharmacological mechanisms of action [35].

Two recent studies have assessed whether a free combination of tiotropium plus a LABA provides superior bronchodilator efficacy compared with single-agent therapy [36, 37]. A total of 71 patients with moderate-to-severe COPD participated in a randomised, double-blind, three-way, 6-week cross-over study and received tiotropium $18 \mu \mathrm{g}$ once daily, formoterol $12 \mu \mathrm{g}$ twice daily or both once daily for three 6-week periods [36]. Pulmonary function was monitored for $24 \mathrm{~h}$ at the end of each treatment period. Although comparative improvements in peak forced expiratory volume in one second (FEV1) and forced vital capacity (FVC) were achieved following the morning dose of the individual treatment regimens, tiotropium was superior $(p<0.05)$ to formoterol in terms of the average FEV1 and FVC during the daytime $(0-12 \mathrm{~h}$ after the morning dose). This is probably due to the substantially longer duration of action of tiotropium [38]. During the night-time period (12$24 \mathrm{~h}$ after the morning dose), no significant differences were found between the single drugs. Higher trough (i.e. $24 \mathrm{~h}$ after the last dose of tiotropium or tiotropium plus formoterol, and $12 \mathrm{~h}$ after the last dose of formoterol) FEV1 values were also observed for tiotropium compared with formoterol $(p<0.05)$. Significantly higher peak and average FEV1 and FVC responses were observed with the combination regimen 
compared with either single-agent therapy. The combination regimen provided additive FEV1 and FVC bronchodilator effects compared with either tiotropium or formoterol alone $(\mathrm{p}<0.0001)$ during the daytime $(0-12 \mathrm{~h}$ after the morning dose $)$ when patients are most active. The value of a once-daily tiotropium plus LABA combination as a therapeutic option is further strengthened by the additive effect during the nighttime period of the 24-h dosing interval, as reflected by the superior average FEV1 (12-24 h after the morning dose) response versus the single agents $(\mathrm{p}<0.02)$ and a trend for higher trough FEV1 compared with formoterol $(p<0.001)$ or tiotropium $(p=0.08)$ alone.

In another double-blind, four-way, 6-week cross-over study, 97 patients with moderate-to-severe COPD were randomised to receive tiotropium $18 \mu \mathrm{g}$ once daily, salmeterol $50 \mu \mathrm{g}$ twice daily, or the free combinations of tiotropium $18 \mu \mathrm{g}$ plus salmeterol $50 \mu \mathrm{g}$ once daily or tiotropium $18 \mu \mathrm{g}$ once daily plus salmeterol $50 \mu \mathrm{g}$ twice daily [37]. Comparative improvements in peak FEV1 and FVC were achieved following the morning dose of the individual treatment regimens; however, tiotropium was superior $(\mathrm{p}<0.05)$ to salmeterol in terms of the average FEV1 and FVC during the daytime (0-12 h after the morning dose). There was no significant difference between the single drugs during the night-time period (12-24 h after the morning dose). Both combination therapies significantly improved trough, peak and average (0-12 h, 0-24 h and 12$24 \mathrm{~h}$ after the morning dose) FEV1 and FVC compared with either of the single-agent therapies $(p<0.01)$. Combination therapy with tiotropium once daily plus salmeterol twice daily produced a further increase in FEV1 and FVC during the nighttime period (12-24 h after the morning dose) compared with the tiotropium plus salmeterol once daily combination regimen $(p<0.01)$. However, there was no significant difference between the two combination regimens during the period of daily activities (0-12 $\mathrm{h}$ after the morning dose). The effects of the combination versus single-agent therapies on dynamic hyperinflation, induced by an increase in breathing frequency, were also compared in this study [39]. Inspiratory capacity and functional residual capacity, surrogate markers of dynamic hyperinflation, were measured at baseline and at the end of each 6-week treatment period in 15 patients. Tiotropium combined with salmeterol once daily or twice daily provided a greater reduction in dynamic hyperinflation compared with either tiotropium or salmeterol alone.

The results of the first prospective study to compare the bronchodilator efficacy of tiotropium combined with a LABA versus a LABA and an ICS were presented at the annual 2005 European Respiratory Society Congress [40]. A total of 592 patients with moderate COPD were randomised to receive a free combination of tiotropium $18 \mu \mathrm{g}$ once daily plus formoterol $12 \mu \mathrm{g}$ twice daily or a free combination of salmeterol $50 \mu \mathrm{g}$ twice daily plus fluticasone propionate $500 \mu \mathrm{g}$ twice daily. Compared with patients receiving treatment with salmeterol plus fluticasone, patients receiving tiotropium plus formoterol experienced greater improvements in FEV1 and FVC over a 12-h period after 6 weeks of treatment. The average FEV1 over $12 \mathrm{~h}$ in the tiotropium plus formoterol group improved by $78 \mathrm{~mL}$ compared with the salmeterol plus fluticasone group $(1.64 \mathrm{~L}$ versus $1.56 \mathrm{~L} ; \mathrm{p}<0.001)$. In addition, compared with salmeterol plus fluticasone, tiotropium plus formoterol improved peak FEV1 by $103 \mathrm{~mL}$ (1.67 L versus $1.78 \mathrm{~L} ; \mathrm{p}<0.0001)$. Trough FEV1 was marginally higher in the tiotropium plus formoterol group compared with the salmeterol plus fluticasone group $(1.51 \mathrm{~L}$ versus $1.49 \mathrm{~L}$; not significant). Compared with the salmeterol plus fluticasone group, the average FVC over $12 \mathrm{~h}$, peak FVC and trough FVC in the tiotropium plus formoterol group improved significantly, by $173 \mathrm{~mL}$ (3.14 L versus $2.99 \mathrm{~L}$; $\mathrm{p}<0.0001)$, $214 \mathrm{~mL}(3.38 \mathrm{~L}$ versus $3.16 \mathrm{~L} ; \mathrm{p}<0.0001)$ and $79 \mathrm{~mL}(2.95 \mathrm{~L}$ versus $2.87 \mathrm{~L} ; \mathrm{p}<0.05)$, respectively.

The results of these studies suggest that maintenance treatment with tiotropium combined with a LABA should be considered in patients with moderate-to-severe COPD whose symptoms are not adequately controlled with a single long-acting bronchodilator. The sustained improvements in bronchodilation and consequent reductions in dynamic hyperinflation with the combination regimens may provide greater improvements in patient-centred outcomes compared with single-agent therapies in this subgroup of patients.

\section{CONCLUSIONS}

Although LABAs have been shown to improve lung function, the efficacy of these agents on patient-centred outcomes, such as dyspnoea, exacerbations and HRQoL, is not consistent across trials, and significant benefits on exercise tolerance have not yet been described. By contrast, the weight of evidence from randomised, controlled clinical trials shows that maintenance treatment with tiotropium provides consistent and sustained improvements in all patient-centred outcomes.

Furthermore, post hoc analyses of the 1-yr trials with tiotropium suggest that tiotropium may reduce the rate of decline in lung function compared with placebo [41]. However, due to the limits of the accuracy and precision by which forced expiratory volume in one second can be measured, a follow-up of $\geqslant 3$ yrs is required to estimate the decline in forced expiratory volume in one second [42]. Therefore, the 4-yr multinational Understanding the Potential Long-term Impacts on Function with Tiotropium (UPLIFT) trial was launched in January 2003 [43]. UPLIFT is the largest study of its kind and the most globally inclusive, involving $\sim 6,000$ chronic obstructive pulmonary disease patients in 37 countries. The primary objective of UPLIFT is to examine whether tiotropium affects the long-term progression of chronic obstructive pulmonary disease, as estimated by the annual decline in forced expiratory volume in one second. Other important outcome measures, including health-related quality of life, exacerbations and mortality, will also be assessed. The first results are expected in 2008.

\section{REFERENCES}

1 Pitta F, Troosters T, Spruit MA, et al. Characteristics of physical activities in daily life in chronic obstructive pulmonary disease. Am J Respir Crit Care Med 2005; 171: 972-977.

2 Oga T, Nishimura K, Tsukino M, et al. Exercise capacity deterioration in patients with COPD: longitudinal evaluation over 5 years. Chest 2005; 128: 62-69.

3 Spencer S, Calverley PMA, Burge PS, Jones PW. Health status deterioration in patients with chronic obstructive 
pulmonary disease. Am J Respir Crit Care Med 2001; 163 : 122-128.

4 Global Initiative for Chronic Obstructive Lung Disease. Global strategy for the diagnosis, management, and prevention of chronic obstructive pulmonary disease, 2005. www.goldcopd.com. Date last accessed: September 26, 2006.

5 Anon. Chronic obstructive pulmonary disease. National clinical guideline on management of chronic obstructive pulmonary disease in adults in primary and secondary care. Thorax 2004; 59: Suppl. 1, 1-232.

6 Littner MR, Ilowite JS, Tashkin DP, et al. Long-acting bronchodilation with once-daily dosing of tiotropium $\left(\right.$ Spiriva $\left.^{\mathrm{TM}}\right)$ in stable COPD. Am J Respir Crit Care Med 2000; 161: 1136-1142.

7 Casaburi R, Briggs DD Jr, Donohue JF, et al. The spirometric efficacy of once-daily dosing with tiotropium in stable COPD. A 13-week multicenter trial. Chest 2000; 118: 1294-1302.

8 Casaburi R, Mahler DA, Jones PW, et al. A long-term evaluation of once-daily inhaled tiotropium in chronic obstructive pulmonary disease. Eur Respir J 2002; 19: 217-224.

9 Donohue JF, van Noord JA, Bateman ED, et al. A 6-month, placebo-controlled study comparing lung function and health status changes in COPD patients treated with tiotropium or salmeterol. Chest 2002; 122: 47-55.

10 Brusasco V, Hodder R, Miravitlles M, et al. Health outcomes following treatment for six months with once daily tiotropium compared with twice daily salmeterol in patients with COPD. Thorax 2003; 58: 399-404.

11 Vincken W, van Noord JA, Greefhorst APM, et al. Improved health outcomes in patients with COPD during $1 \mathrm{yr}^{\prime}$ 's treatment with tiotropium. Eur Respir J 2002; 19: 209-216.

12 O'Donnell DE, Flüge T, Gerken F, et al. Effects of tiotropium on lung hyperinflation, dyspnoea and exercise tolerance in patients with COPD. Eur Respir J 2004; 23: 832-840.

13 Casaburi R, Kukafka D, Cooper CB, Witek TJ Jr, Kesten S. Improvement in exercise tolerance with the combination of tiotropium and pulmonary rehabilitation in patients with COPD. Chest 2005; 127: 809-817.

14 Tonnel AB, Perez T, Grosbois JM, Bravo M-L, Brun M. Improvement in HRQoL of COPD patients after 9 months' treatment with tiotropium bromide: use of a new scale for daily medical practice. Eur Respir J 2005; 26: 290 s.

15 Niewoehner DE, Rice K, Cote C, et al. Prevention of exacerbations of chronic obstructive pulmonary disease with tiotropium, a once-daily inhaled anticholinergic bronchodilator: a randomized trial. Ann Intern Med 2005; 143: 317-326.

16 Maltais F, Hamilton A, Marciniuk D, et al. Improvements in symptom-limited exercise performance over $8 \mathrm{~h}$ with once-daily tiotropium in patients with COPD. Chest 2005; 128: 1168-1178.

17 Verkindre C, Bart F, Aguilaniu B, et al. The effect of tiotropium on hyperinflation and exercise capacity in chronic obstructive pulmonary disease. Respiration 2006; 73: $420-427$.
18 Dusser D, Bravo M-L, Iacono P. The effect of tiotropium on exacerbations and airflow in patients with COPD. Eur Respir J 2005; 27: 547-555.

19 Rennard SI, Anderson W, ZuWallack R, et al. Use of a longacting inhaled $\beta_{2}$-adrenergic agonist, salmeterol xinafoate, in patients with chronic obstructive pulmonary disease. Am J Respir Crit Care Med 2001; 163: 1087-1092.

20 van Noord JA, de Munck DRAJ, Bantje T, et al. Long-term treatment of chronic obstructive pulmonary disease with salmeterol and the additive effect of ipratropium. Eur Respir J 2000; 15: 878-885.

21 Mahler DA, Donohue JF, Barbee RA, et al. Efficacy of salmeterol xinafoate in the treatment of COPD. Chest 1999; 115: 957-965.

22 Boyd G, Morice AH, Pounsford JC, et al. An evaluation of salmeterol in the treatment of chronic obstructive pulmonary disease (COPD). Eur Respir J 1997; 10: 815-821.

23 Grove A, Lipworth BJ, Reid P, et al. Effects of regular salmeterol on lung function and exercise capacity in patients with chronic obstructive airways disease. Thorax 1996; 51: 689-693.

24 Ulrik CS. Efficacy of inhaled salmeterol in the management of smokers with chronic obstructive pulmonary disease: a single centre randomised, double blind, placebo controlled, crossover study. Thorax 1995; 50: 750-754.

25 Aalbers R, Ayres J, Backer V, et al. Formoterol in patients with chronic obstructive pulmonary disease: a randomized, controlled, 3-month trial. Eur Respir J 2002; 19: 936-943.

26 Rossi A, Kristufek P, Levine BE, et al. Comparison of the efficacy, tolerability, and safety of formoterol dry powder and oral, slow-release theophylline in the treatment of COPD. Chest 2002; 121: 1058-1069.

27 Dahl R, Greefhorst LAPM, Nowak D, et al. Inhaled formoterol dry powder versus ipratropium bromide in chronic obstructive pulmonary disease. Am J Respir Crit Care Med 2001; 164: 778-784.

28 Mahler DA, Wire P, Horstman D, et al. Effectiveness of fluticasone propionate and salmeterol combination delivered via the Diskus device in the treatment of chronic obstructive pulmonary disease. Am J Respir Crit Care Med 2002; 166: 1084-1091.

29 Calverley P, Pauwels R, Vestbo J, et al. Combined salmeterol and fluticasone in the treatment of chronic obstructive pulmonary disease: a randomised controlled trial. Lancet 2003; 361: 449-456.

30 Szafranski W, Cukier A, Ramirez A, et al. Efficacy and safety of budesonide/formoterol in the management of chronic obstructive disease. Eur Respir J 2003; 21: 74-81.

31 Rutten-van Mölken MPMH, Roos B, van Noord JA. An empirical comparison of the St George's Respiratory Questionnaire (SGRQ) and the Chronic Respiratory Disease Questionnaire (CRQ) in a clinical trial setting. Thorax 1999; 54: 995-1003.

32 Jones PW, Bosh TK. Quality of life changes in COPD patients treated with salmeterol. Am J Respir Crit Care Med 1997; 155: 1283-1289.

33 Hanania NA, Darken P, Horstman D, et al. The efficacy and safety of fluticasone propionate $(250 \mu \mathrm{g}) /$ salmeterol $(50 \mu \mathrm{g})$ combined in the Diskus inhaler for the treatment of COPD. Chest 2003; 124: 834-843. 
34 Calverley PM, Boonsawat W, Cseke Z, et al. Maintenance therapy with budesonide and formoterol in chronic obstructive pulmonary disease. Eur Respir J 2003; 22: 912-919.

35 Global Initiative for Chronic Obstructive Lung Disease strategy for the diagnosis, management and prevention of chronic obstructive pulmonary disease: an Asia-Pacific perspective. Respirology 2005; 10: 9-17.

36 van Noord JA, Aumann JL, Janssens E, et al. Comparison of tiotropium once daily, formoterol twice daily and both combined once daily in patients with COPD. Eur Respir J 2005; 26: 214-222.

37 van Noord JA, Aumann J, Janssens E, Mueller A, Cornelissen PJG. A comparison of the 24-hour bronchodilator effect of tiotropium QD [TIO], salmeterol BID [SALM] or their combination in COPD. Proc Am Thorac Soc 2005; 2: A542.

38 Donohue JF, Menjoge S, Kesten S. Tolerance to bronchodilating effects of salmeterol in COPD. Respir Med 2003; 97: 1014-1020.
39 van Noord JA, Smeets JJ, Otte A, et al. The effect of tiotropium, salmeterol and its combination on dynamic hyperinflation in COPD. Proc Am Thorac Soc 2005; 2: A542.

40 Rabe KF, Timmer W, Sagriotis A, Viel K. Comparison of a combination of tiotropium and formoterol to salmeterol and fluticasone in moderate COPD. Eur Respir J 2005; 26: $14 \mathrm{~s}$.

41 Anzueto A, Tashkin D, Menjoge S, Kesten S. One-year analysis of longitudinal changes in spirometry in patients with COPD receiving tiotropium. Pulm Pharmacol Ther 2005; 18: 75-81.

42 Decramer M, Gosselink R, Rutten-van Molken M, et al. Assessment of progression of COPD: report of a workshop held in Leuven, 11-12 March 2004. Thorax 2005; 60: 335-342.

43 Decramer M, Celli B, Tashkin DP, et al. Clinical trial design considerations in assessing long-term functional impacts of tiotropium in COPD: the UPLIFT trial. J COPD 2004; 1 : 303-312. 